Nuntius Antiquus, Belo Horizonte, v. 11, n. 2, p. 9-32, 2015

\title{
Afetos aristotélicos em Shakespeare e Freud: um exercício de tradução
}

\section{Aristotelian affects in Shakespeare and Freud: an exercise in translation ${ }^{1}$}

\author{
Ana Vicentini de Azevedo \\ Psicanalista (SP) \\ Association Psychanalytique Encore (Paris) e UnB \\ anavica2009@gmail.com
}

La poésie est création d'un sujet assumant un nouvel ordre de relation symbolique au monde.

Jacques Lacan

Resumo: O presente trabalho perfaz um exercício de tradução da definição dos afetos (páthe), tal como formulada por Aristóteles na Retórica, para outros campos da experiência humana, em particular, a tragédia Rei Lear, de Shakespeare, e a teoria psicanalítica (Freud e Lacan). Nesse percurso, elegemos a tragédia como locus privilegiado da discussão,

\footnotetext{
${ }^{1}$ Texto apresentado no evento "I Seminário Docere, Delectare et Mouere: Emoções Aristotélicas no Cinema" (Centro de Convenções do Complexo Santuário do Caraça, na região da cidade de Santa Bárbara, Minas Gerais, de 10 a 13 de março de 2015, <www. letras.ufmg.br/doceredelectareetmovere >) organizado por Maria Cecília de Miranda Nogueira Coelho (Departamento de Filosofia da FAFICH-UFMG), como coordenadora geral, e por Helcira Maria Rodrigues de Lima, Sérgio Alcides Pereira do Amaral e Teodoro Rennó Assunção (todos três da FALE/UFMG), e promovido pelo Grupo de Pesquisa "Retórica e Argumentação", do CNPq e UFMG (FAFICH-FALE), pelo "Núcleo de Estudos Antigos e Medievais" (NEAM) do CNPq e UFMG (FALE-FAFICH), com apoio da CAPES, da FAPEMIG, do PPG-FIL da FAFICH/UFMG, do PÓS-LIN e do PÓS-LIT da FALE/UFMG.
} 
na qual propomos possíveis leituras para a problemática dos afetos, no campo conceitual das pulsões, e na dimensão da mimese, da catarse e da sublimação. Como é próprio a todo processo de transposição de uma ideia para outras linguagens e idiomas, esse exercício marca-se pela contaminação mútua dos campos de conhecimento postos em diálogo.

Palavras-Chave: afetos; pulsão; tragédia; mimese; catarse; sublimação; Aristóteles; Shakespeare; Freud; Lacan.

Abstract: The present paper aims at carrying out an exercise in translation of the Aristotelian notion of affects (páthe) as developed in the Rhetoric, into other fields of the human experience. In particular, our analysis will focus on Shakespeare's King Lear and on psychoanalytic theory (Freud and Lacan) in order to bring to the fore possible readings of the question of the affects, within the framework of the notions of mimesis, catharsis and sublimation. As characteristic of every process of transposition of a particular idea to (an) other language(s), this exercise bears marks of the mutual contamination that the fields of knowledge in question carry into the other.

Keywords: affects; drives; tragedy; mimesis; catharsis; sublimation; Aristotle; Shakespeare; Freud; Lacan.

Recebido em 15 de maio de 2015 Aprovado em 18 de junho de 2015

\section{Para introduzir}

Esse trabalho é resultado de três momentos distintos, que ora se entretecem: 1) a preparação para uma apresentação no Seminário Docere, Delectare et Mouere: emoções aristotélicas no cinema; 2) as exposições desse e dos demais trabalhos que compuseram o seminário e a riqueza dos debates; 3) as reflexões que pude fazer, après-coup, sobre a ideia inicial. O que se segue, então, é o precipitado desses três tempos.

As questões que me moveram, desde a convocatória para o Seminário, partiram da tragédia Rei Lear, de Shakespeare. Dentre as quatro grandes tragédias do bardo, Rei Lear (1605-1606) situa-se entre Othello (c. 1604) e a sombria Macbeth (1605-1606). A quarta delas, Hamlet, é de c. 1600 , na virada do período elizabetano para o jacobino. É dessa última que retiro uma porta de entrada para tratarmos da questão dos afetos. 
Diz o jovem Hamlet a seu amigo e scholar, Horácio: Give me that man/ That is not passion's slave, and I will wear him/In my heart's core (III, ii, 71-73). ${ }^{2}$ Sob a égide do instigante debate ético entre Hamlet e Horácio (e é esse um dos grandes eixos temáticos da obra), Lily Campbell escreve uma obra fundamental sobre os afetos nas tragédias de Shakespeare, cuja leitura é referencial até os dias de hoje. Campbell destaca Rei Lear como a tragédia da ira (wrath) na velhice (CAMPBELL, 1930, p. 175-207). Inspirada por essa autora, afasto-me dela, porém, para situar a premissa basal nesse trabalho: Lear é não apenas uma tragédia sobre a ira na/da velhice, mas é, sobretudo, uma tragédia sobre os afetos, ou ainda, é $a$ tragédia dos afetos. Não se trata somente dos afetos particularmente trágicos, como tratados por Aristóteles na Poética, mas da tragédia que constituem os afetos na vida dos humanos. Tal assertiva pede vários desdobramentos; alguns dos quais serão nosso objeto de atenção no que se segue.

\section{Plano inicial}

Começamos por colocar em primeiro plano a complexa definição que Aristóteles dá sobre os afetos, ${ }^{3}$ no livro II da Retórica. Sob uma perspectiva ampla, pode-se dizer que faremos aqui um exercício de tradução dessa definição para outros campos da experiência humana:

The emotions [páthe] are all those affections which will cause men to change [metabállontes] their opinion in regard to their judgements [kriseis], and are accompanied by pleasure [hédoné] and pain [lypé]; such as anger [orgé]], pity [éleos], fear [phóbos], and all similar emotions and their contraries. ${ }^{4}$ [ARISTOTLE, 1994, p. 173 (II.I.8 ff.)]

\footnotetext{
${ }^{2}$ Todas as referências a Hamlet são tiradas da Arden Edition (1989). Adota-se aqui a praxe para a citação de textos shakespearianos. Os números em algarismos romanos e em caixa alta referem-se ao ato; os em romano minúsculo à cena; e os algarismos arábicos ao(s) número do(s) verso(s).

${ }^{3}$ Desde já, a tradução de páthos que adotamos aqui é "afeto", e não emoção ou sentimento, por razões que ficarão claras no decorrer do trabalho.

4 "Os afetos são todas as afecções que fazem com que os seres mudem de opinião em relação a seu juízo, e vêm acompanhadas por prazer e dor, tais como a ira, a compaixão e o terror, e todos os afetos similares, bem como seus contrários".
} 
Três aspectos iniciais nesse trecho merecem destaque. O primeiro deles diz respeito a algo que é de importância capital para a compreensão do humano e do que torna esses seres, humanos; qual seja, a dimensão de linguagem que envolve e emoldura toda a discussão aristotélica sobre os afetos. Não é à toa que essa discussão se dá em um livro chamado Retórica! Dito de modo mais explícito: os afetos são um produto da linguagem (como os seres humanos, como veremos adiante). Nesse sentido, a taxinomia levada a efeito por Aristóteles na Retórica é muito mais do que uma descrição de fenômenos naturais ou psicologizantes. Ela é, sim, um ato de nomeação que, como tal, cria um mundo dos afetos que ele põe em evidência como centrais às trocas entre os humanos e a suas mudanças.

$\mathrm{O}$ segundo aspecto reside no fato de essas afecções entre e dos humanos serem sempre objeto de mudança. Nesse trecho da Retórica, a ideia de mudança está associada à de passagem de um estado para seu contrário. Porém, essa não é a única acepção de mudança em Aristóteles, como se sabe. A ideia de mudança que figura na Metafísica, por exemplo, compreende as dimensões de criação (génesis) e de destruição (phthorá) (Z 7-9, ARISTOTE, 1962, p. 379). Uma perspectiva que nos parece mais produtiva para pensarmos a produção humana, em particular a poética. No caso específico da tragédia, a mudança constitui o télos da experiência trágica, na medida em que visa a produzir uma alteração (catarse) nos afetos de terror e compaixão. No que se segue, pretendemos explorar uma possível conjugação (ou tradução) entre a mudança nos seres (metabállontes) e a intricada noção de catarse.

Rei Lear constitui uma fecunda experiência poética de onde podemos extrair lições importantes para um desdobramento possível, no plano da crítica literária e da psicanálise, da noção de catarse. Associamse aqui, para ser discutidos adiante, os temas de mudança, catarse e afeto.

Do ponto de vista do funcionamento psíquico, a mudança no registro dos afetos toca de perto na questão da sublimação, da transformação de uma demanda de satisfação pulsional (que poderia ser encontrada, como a ponta de um iceberg, em um afeto como "ódio", por exemplo), em outra coisa, mais satisfatoriamente duradoura e menos imperativa. Sublimação é um conceito intricado para a psicanálise. Em um raro momento de definição acessível, Freud define-a como um processo em que as moções pulsionais se desviam da busca de satisfação imediata e "assim colocam essa energia à disposição do desenvolvimento cultural sob a forma de tendências "sublimadas"” (FREUD, 1924[1923]/1961, 
p. 207). ${ }^{5}$ Ou seja, a pulsão, em sua incessante visada à satisfação, está sempre a pedir mais, e mais objetos para que esse objetivo seja atingido. Parte do problema reside no fato de que não há, nem haverá, um objeto (ou uma série de objetos) que possa satisfazer às demandas pulsionais. Assim, o processo de sublimação constitui uma alternativa para se obter satisfação, prescindindo desses objetos, ou, como indicou Lacan, elevando o objeto à dignidade da Coisa (LACAN, 1986). O processo de mudança chamado de sublimação conjuga-se aqui, em uma hipótese interpretativa, com a metabolé aristotélica, tão central no tratado dos afetos (e nos afetos). Em meio às diversas modalidades da ideia de mudança em Aristóteles, ressaltamos que a acepção a ser privilegiada na análise de Lear diz respeito à mudança tanto em seu aspecto criador (génesis), quanto destruidor (phthorá) (ARISTOTE, 1962, p. 379).

Esse caráter duplo da metabolé traz à baila não somente a noção de sublimação, no que ele comporta de mudança, de criação e de destruição, como também pode se aproximar do intricado processo de produção do efeito catártico. Nesses cruzamentos, cabe interrogar: em que medida Aristóteles constrói um quiasma freudiano no sentido de sublinhar o caráter sublimatório da catarse (ou o caráter catártico da sublimação)? Essa é uma pergunta central nesse trabalho.

O terceiro ponto de destaque na definição aristotélica diz respeito à questão do julgamento, a krísis. ${ }^{6}$ Adotamos aqui concepção filosófica bastante genérica de que um julgamento trata de uma afirmação ou de uma negação, e que pode ser falso ou verdadeiro (MORA, 1987, p. 435439). Da complexidade que gera essa noção e de seus desdobramentos na tradição filosófica, desde Aristóteles, ressaltamos que ela comporta aspectos lógicos, metafísicos e psicológicos.

\footnotetext{
${ }^{5}$ Todas as citações à obra de Freud são tiradas da Standard Edition of the Complete Psychological Works of Sigmund Freud e seguem a praxe internacionalmente adotada: a primeira data entre parênteses refere-se ao ano da primeira publicação escrita do texto; o ano entre colchetes à sua escrita. O último refere-se ao ano de publicação da edição que está sendo utilizada.

${ }^{6}$ Os comentários e problematizações feitos por Ackrill sobre o desenvolvimento da krísis em De interpretatione, de Aristóteles, foram referência aqui (1990).
} 


\section{Um plano meta-psicológico}

Na Retórica, a dimensão "psicológica" do julgamento parece ser a mais saliente, tendo em vista, por exemplo, a listagem dos afetos ali tratados. Nessa perspectiva - e em uma tentativa de compor um quadro teórico-conceitual para discutir a questão dos afetos em Rei Lear e, sobretudo, com a peça -, Freud entra em cena, tanto como herdeiro da tradição filosófica sobre a questão do julgamento, quanto com sua contribuição no sentido de aproximar lógica, metafísica e psicologia, ou, de forma mais radical, da supressão do hiato entre a vida do intelecto e a vida dos afetos. Esses se juntam no que Freud entende por "mental", um aparato psíquico, composto por três instâncias funda-mentais, que estão sempre em tensão conflitiva, a saber: o inconsciente, o sistema percepção-consciência e o pré-consciente. ${ }^{7}$

O julgamento, para ele, é a continuação de um processo estrutural na constituição do psiquismo e, portanto, do humano, a saber: o processo originário de afirmação (Bejahung) e de expulsão (Ausstossung) que é levado a efeito pela criança na diferenciação entre mundo externo e interno. A afirmação une interno e externo (inicialmente sob a égide do princípio do prazer); e a expulsão visa a afastar do "eu" o que lhe é estranho, o que lhe causa desprazer. Porém, essa dicotomia não se sustenta na teoria freudiana (jamais um sistema teórico fechado e conclusivo), na medida em que o mental passa a ser pensado não mais como regido pelo princípio do prazer, mas, a partir de 1920, pelo "mais além do princípio do prazer". ${ }^{8}$

Com o princípio dialético adotado com o "mais além", Freud pode desenvolver, ou matizar, a expulsão (Ausstossung) em termos de três tipos

\footnotetext{
${ }^{7}$ A Intrepretação dos Sonhos (1900/1958) constitui a principal fonte de referência à primeira tópica freudiana.

8 "Para além do princípio do prazer" é um texto de Freud que constitui um turningpoint na teoria psicanalítica (1920/1955), na medida em que supera a dicotomia prazerdesprazer, interno-externo, privilegiado no domínio do ego, do ego-lust, para trazer à baila, sempre sob a inspiração da clínica, a dialética que compõe o aparelho psíquico. Este, além de desconhecer o princípio da não contradição, basal à lógica clássica, articula prazer e dor, sob a égide da pulsão de morte: todo organismo vivo visa ao estado de supressão de toda a tensão (...). A esse princípio de Nirvana, Freud chama de pulsão de morte. Prazer na dor é algo que transborda as fronteiras do eu-prazer, soberanamente consciente, que visa ao belo e ao bem (kalòs kagathós). Ecoemos aqui a citação de Aristóteles acima, em particular sua articulação entre dor e prazer (lypé kaì hédoné).
} 
de "negatividade": a denegação (Verneinung), ${ }^{9}$ a recusa (Verleugnung) e a foraclusão, forma aportuguesada para o neologismo proposto por Lacan para o termo alemão Verwerfung (HANNS, 1996). Sinteticamente, podemos traduzir tais negações como: 1) "esse sonho não tem nada a ver com minha mãe" (ou seja, afirma-se, negando); 2) "eu sei que é ficção, mas, mesmo assim, o filme me comoveu às lágrimas" (aceitação e recusa); 3 ) "isso deve ser eliminado, rejeitado" (posto que intolerável). ${ }^{10}$ Qualquer uma dessas formas de negação pressupõe, no entanto, a Bejahung primordial. Só se pode negar algo que já está, mesmo que isso seja o "nada". Dito de outro modo, há que se ter uma inscrição primordial para que todo e qualquer outro processo simbólico - presença e ausência - possa ser levado a efeito no mundo do sujeito e no sujeito no mundo.

Retomando a dimensão do julgamento, da krísis como princípio de separação e de possibilidade de existência, vale observar que, sob a lupa de Freud, a separação entre juízo de existência (é ou não é) e juízo de atribuição (tem ou não tem) pode embaralhar a distinção - confortável - na qual se assenta certa tradição filosófico-científica, entre sujeito e objeto. Ao enunciar o julgamento, e.g.: "eu não sou João", Maria pode afirmar seu ser Maria, como pode igualmente afirmar seu desejo de ser João. E mais, ela pode, também, ser sujeito e objeto desse julgamento. Evocando as palavras de Freud, "o eu não é senhor em sua própria casa" (FREUD, 1917/1955, p. 143). Em outras palavras, concomitantemente a esse "eu" que é sujeito de uma sentença, há outro que diz mais do que o sujeito que diz e do que o objeto do dito. Le langage joue entièrement dans l'ambiguité, et la plupart du temps, vous ne savez absolumenet rien de ce que vous dites (LACAN, 1981, p. 130). Com Lacan, os fundamentos linguísticos da descoberta freudiana - o inconsciente -, são evidenciados em termos de um hiato instransponível entre o sujeito do enunciado e o sujeito da enunciação; em suma, um sujeito dividido. ${ }^{11}$ É nesse terreno pantanoso que entramos em Rei Lear.

\footnotetext{
${ }^{9}$ Título alemão do texto "A negação", de Freud (1925/1961).

${ }^{10}$ Em seu notável seminário sobre as psicoses (1981/1956), Lacan aproxima a Ausstossung da Verwerfung (LACAN, 1981, p. 85-101). Adotamos essa confluência para discutir Rei Lear.

${ }^{11}$ LACAN, 1966 ("Fonction et champ de la parole et du langage en psychanlyse"e "L'instance de la lettre dans l'inconscient ou la raison depuis Freud"). Nessa perspectiva, alguns protocolos acadêmico-científicos, tais como a proibição do uso do pronome
} 


\section{A primeira cena do Lear: da Ausstossung à Verwerfung}

Peter Brook é, notoriamente, um dos mais importantes diretores de Shakespeare que a Inglaterra já teve nos dois últimos séculos. Sua produção, no teatro e posteriormente no cinema, garante-lhe esse lugar de destaque, face aos desafios que representa uma montagem de qualquer obra shakespeariana. E é a leitura fílmica que Brook faz de Rei Lear (de 1971), que tomo como foco privilegiado dessa discussão.

O filme abre com uma tomada, em ritmo bastante lento, de homens comuns, estáticos. A câmera passeia por seus rostos, evidenciando os olhos que se dirigem, apreensivos, para algum lugar, para "fora da tela". Nenhum único som é produzido ao longo dessa longa cena (aproximadamente um minuto e meio) que pode vir a ser, justamente por seu clima tenso e silencioso, quase insuportável. O corte da cena é feito de modo marcante, para que não passe desapercebido.

A tomada seguinte é uma sala oval, onde aparece, em primeiro plano, um grande objeto "totêmico", cuja proeminência captura o olhar, deixando quase desapercebidas as pessoas que compõem o círculo. $\mathrm{O}$ enquadramento é de tal precisão que traz também para o campo visual uma abertura, uma passagem ao fundo direito da sala. Dela "surge" uma porta, cujo fechamento brusco é o primeiro som que se tem no filme. Fecha-se a sala/mundo, começa o drama.

Segue-se outro corte brusco, e o foco recai sobre a face enigmática e ameaçadora - de Paul Scofield, que interpreta Lear. O longo close-up, também em um silêncio amedrontador, aguarda alguma manifestação do protagonista. Quase como um eco ao fechamento da porta, Lear lentamente abre a boca e diz: know, seguido de uma significativa pausa. Só se pode saber que se trata do verbo quando se conhece o texto de Shakespeare. Na leitura fílmica que faz Brook, a homofonia entre know e no é posta em relevo justamente pela longa pausa que segue essa enunciação. Ou seja, a primeira palavra do filme é "não" (já indicado pela porta que se fechou).

Ao que Lear diz não? E de forma tão incisiva (mas nada agressiva, deve-se notar)? Uma linha interpretativa possível seria um não a isso que a câmera nos mostrou na abertura do filme: um universo de pessoas

pessoal, tornam-se inócuos. A ausência de um "eu” gramatical não diz nada a respeito de uma maior ou menor objetividade. O sujeito fala, sempre. 
comuns. E então, seu mundo privilegiado seria esse da pequena corte, que se fecha em torno de si mesma. Seria uma espécie de Ausstossung, de expulsão do mundo dos reles súditos ${ }^{12}$ em detrimento do mundo dos prazeres reconfortantes da corte.

Porém, Brook é um bom leitor de Shakespeare e sabe fazer figurar a complexidade de seus universos dramáticos. Após a pausa negativa, ouvimos de Lear que ele nos fará saber de seu darker purpose $(\mathrm{I}, \mathrm{i}, 35):{ }^{13}$ não apenas ele irá dividir seu reino entre suas três filhas, como, sobretudo, se retirará dele. Saber e negação se entrelaçam, com uma economia temporal aguda, própria aos grandes dramas.

Brook também demonstra desde cedo sua mestria como leitor cinematográfico de Shakespeare, ao pôr em relevo a lógica do espelhamento, do counterfoil ${ }^{14}$ que marca as peças desse último. Em um paralelismo magistral, Brook faz ressoar o fechamento da porta e o "não" inicial, agora com a elevada gravidade que convém ao trágico. Com igual fineza, ele traz à cena uma questão que perpassa a tradição trágica - a ironia, especialmente entre um suposto saber e sua negação. Lear, tal como Édipo, acredita que sabe, muito embora tenha admitido tratar-se de um darker purpose, um propósito sombrio, obscuro, misterioso, secreto, até para ele mesmo. ${ }^{15}$

A divisão do reino entre as filhas é um ato sobre o qual Lear nada quer saber. Sua decisão é tomada com o intuito de se livrar (unburden) das incumbências de ser rei para poder gozar - e esse é um verbo prenhe na tragédia - uma velhice com menos responsabilidades (I, i, 35-40). Vários nós se atam aqui. O primeiro deles é sua demissão do mundo

${ }^{12}$ Essa leitura socializante é privilegiada no filme homônimo do diretor soviético Kozintesev, também de 1971.

${ }^{13}$ Todas as referências ao texto King Lear de Shakespeare (1994) são retiradas da balizada edição Arden das obras do autor. Após cada citação, indico o número do ato em algarismos romanos maiúsculos, seguido do número da cena (em romanos minúsculos) e do verso, em algarismos arábicos, conforme a praxe internacionalmente adotada para citações de Shakespeare.

${ }^{14}$ Termo bastante utilizado na crítica shakespeariana para se referir a personagens que são usadas como espelho reflexivo (diferencial ou exponencial) do protagonista.

${ }^{15}$ Chama atenção o fato desse comentário, tão importante e significativo para a estruturação da tragédia, ter sido cortado por Brook. Mantenho o original em inglês em face da concisão poética que ele traz e que se perde nas múltiplas acepções necessárias para traduzi-lo. 
que Lear decreta: ou seja, sua expulsão do mundo como rei e soberano, sua Ausstossung da kin(g)ship. Ele decreta, paradoxalmente, sua ek-sistência. Um paradoxo que Hamlet já havia expresso em um quiasma poético: The king is with the body, but the body is not with the king (IV, iii, 24-25). Como instância da lei, como agente da ordem simbólica, ${ }^{16}$ Lear decreta sua própria exclusão do mundo para se tornar "um corpo de nada" (Hamlet, IV, iii, 25).

A violência mortífera do ato é acompanhada por outro ato, de igual violência, só que velada. Lear vai distribuir suas terras na medida do amor que lhe jurarem suas três filhas. A impossibilidade dessa moeda de troca simbólica remete-nos ao âmbito do páthos, de maneira patética e patológica. Uma primeira impossibilidade: como medir o amor? If it be love indeed, tell me how much, pede Cleópatra a Antônio, na peça homônima de Shakespeare. A resposta do imperador é contundente: There's beggary in the love that can be reckoned [SHAKESPEARE, 1971, p. 1 (I, i, 14-15)]. Como bom "médico de alma", Shakespeare começa a nos abrir algumas portas de entrada no reino dos afetos.

$\mathrm{O}$ amor avaro de Goneril e Regan ganha força em suas juras repletas de esvaziamentos retóricos. A primeira declara: I love you more than word can wield the matter, ou seja, trata-se de um amor que transborda a esfera do humano, do que comportam as palavras: A love that makes breath poor and speech unable; Beyond all manner of so much I love you (I, i, 54-60).

Assim Goneril instaura o duelo retórico entre as irmãs, ao qual Lear assiste com um misto de deleite e descrédito. Os golpes de linguagem deferidos por Regan vêm igualmente inflados de "tópicos de inexpressibilidade", como designam os retóricos (KERMODE, 2000, p. 185): I profess/ Myself an enemy to all other joys/ Which the most precious square of sense possesses (I, i, 71-73).

Entre uma e outra fala das irmãs, Cordélia faz um aparte e um corte, com uma pergunta reveladora: What shall Cordelia speak? Espectadora de si mesma e da patética pantomima encenada pelas irmãs, ela indica seu lugar de fala e de afeto: Love, and be silent (I, i, 61-62).

\footnotetext{
${ }^{16}$ Para uma visão detalhada sobre a função paterna e a estruturação da ordem simbólica, remeto a Azevedo (2001), onde também estão esmiuçados os registros lacanianos de Real, Simbólico e Imaginário, em uma análise da Oresteia, de Ésquilo.
} 
Curiosa posição de Goneril e Regan no duelo amoroso orquestrado por Lear. Ao invés de serem elas o objeto de uma disputa amorosa, como é próprio ao amor cortês, as duas irmãs são colocadas na posição de "pretendentes" (tradicionalmente ocupada pelo homem), e desempenham esse papel com todo vigor viril (uma posição que se robustece ao longo da peça e do filme).

Até agora (em somente 73 versos), Lear já construiu para si um lugar impossível: decretou sua própria expulsão do mundo simbólico, ao mesmo tempo em que pede para ser integrado a ele através dos laços de amor (de philía, de éros, de storgée). A língua inglesa deixa subsumido em um único substantivo uma amplitude de laços eróticos. No caso de Lear, essa indiferenciação é oportuna no sentido de sublinhar a voracidade, não apenas amorosa, que caracteriza a personagem.

Sua pressa em livrar-se de seu ser de "rei", juntamente com a demanda de amor além de qualquer medida, o precipitam no erro trágico fundamental: a desmedida (onde confluem a hamartía e a hýbris). De fato, Lear passa a ser a negação do princípio grego do médèn ágan ("nada em excesso"): All their errors are due to excess, Aristóteles evocando Quílon, na Retórica [ARISTOTLE, 1994, p. 251 (II, 1389b 14)].

\section{0 retorno (no) real}

O humano, em sua constituição basal, é uma questão para vários campos do conhecimento. A lógica ternária constitui uma via frutífera para pensar essa constituição, em especial seus desvios, como o excesso, por exemplo. Desde o pensamento mítico (e.g., as Moiras como figuração dos três tempos fundamentais do ser humano), até o psicanalítico (imbuído também de sua própria mitologia), ele está marcado por essa lógica. Shakespeare não foge à tradição. Na perspectiva triádica, a entrada de Cordélia, a terceira filha, é de relevância especial. ${ }^{17}$ Tudo foi até aqui construído para culminar no momento em que ela deve dizer seu amor, grandiosamente. Ao invés disso, Brook ressalta o lugar terceiro e diverso de Cordélia em um coup de cinéma fantástico: as intervenções das duas primeiras filhas foram precedidas, em primeiro plano, por urnas, ou

\footnotetext{
${ }^{17}$ Freud dedica um belo ensaio a essa questão que ele destaca de duas peças de Shakespeare - O Mercador de Veneza e Rei Lear - em seu "The theme of the three caskets" (1913/1961).
} 
escrínios, que cada uma delas carrega. Importante notar que o tamanho dos objetos decresce na medida em que cada uma dá um passo à frente para fazer sua performance amorosa. Quando chega a vez de Cordélia, a urna aparece apenas parcialmente, um objeto parcial, como são os objetos simbólicos.

Indico apenas uma possibilidade, obviamente psicanalítica e analiticamente óbvia, da coalescência entre as urnas e a genitália feminina. Elas podem ser tomadas como indícios de uma feminilidade (womanhood) tão grandiosamente vazia quanto as palavras de suas detentoras.

Mas Brook não nos deixa simplificar Shakespeare. A urna tão diminuta de Cordélia reflete, especular e espetacularmente, o corte que essa personagem irá empreender tanto na mascarade encenada pelas irmãs como na lógica (no lógos) posta em cena até agora. Sua resposta à demanda de amor de Lear é: Nothing.

Sabemos que no campo semântico do inglês shakespeariano, nothing pode ter a acepção de genitália feminina. ${ }^{18}$ Porém, o jogo de espelhos, tão estrutural nessa peça, se faz presente aqui de modo eloquente. O nothing de Cordélia faz retornar, ampliada e amplificadamente, o não que Lear diz a si e ao mundo. Cordélia faz para Lear o que a arte deve fazer no pequeno tratado sobre estética que Hamlet nos oferece: ela holds the mirror up to nature (III, ii, 22), desvelando ao pai/rei a dimensão do abismo simbólico no qual ele se precipitou, e no qual ele irá, real-mente, em breve se precipitar. Cordélia não somente diz não ao jogo de Lear, mas diz não ao seu não; isto é, ela perfaz um gesto afirmativo, uma Bejahung que inclui o amor ao pai, mas não da forma mortiferamente absoluta que ele pede (e que as irmãs fazem de conta que dão). ${ }^{19}$

E, também em um jogo especular, como uma cena dentro da cena, onde se embaralham posições no âmbito da incerteza e do equívoco em que nos joga a linguagem, Lear expulsa Cordélia do (seu) mundo, condenando-a ao exílio no qual ele, tal como Édipo, em Colono, irá vagar por grande parte da peça. O exílio de Cordélia reflete, retroativamente, o exílio simbólico, a foraclusão em que Lear se projetou com seu know/no inicial.

\footnotetext{
${ }^{18}$ Cf. Hamlet de SHAKESPEARE, 1989, p. 295(III, ii, 121-130).

${ }^{19}$ Impossível não fazer notar a semelhança estrutural entre a posição de Cordélia e a posição do analista.
} 
Em outras palavras, o exílio de Lear não é somente territorial, geográfico, mas, sobretudo, mental. Na medida em que avança o drama - e Brook mostra isso de forma magistral -, Lear vai se destituindo de todas as sustentações que lhe garantiam um lugar no mundo: terras, súditos, serviçais, cavalos, roupas, amor, lealdade; em suma, ele entra em um processo de destituição subjetiva gradual, mas avassaladora.

Brook figura tal processo em um setting que provoca calafrios - inóspito, gelado, um descampado onde há apenas solidão e vazio. Shakespeare chama esse lugar, bem antes de Freud, de loucura. Loucura essa que não tem nada de patológica, posto que there's method in madness. ${ }^{20}$ No jogo especular, Lear será sempre acompanhado por seu Fool, seu bobo, seu louco, tão louco que pode dizer tudo o que está recalcado, tanto no herói como nas demais personagens:

Fool: Thou should'st not have been old till thou hadst/ been wise.

Lear: O! Let me not be mad. Not mad, sweet heaven (...) (I, v, 41-43)

Esse lugar que Lear tanto teme e que o Fool he adverte para evitar, a psicanálise chama de real, ou seja, aquilo que está fora, excluído do mundo simbólico e, portanto, do que as palavras podem circunscrever e dizer. Esse real devastador, mortífero em que Lear se lança é da ordem do inumano; é um mundo "fora do mundo". Essa condição antecipa uma tese que Lacan desenvolverá a respeito da negação e do papel que ela representa na estruturação do psiquismo. Aquilo que é expulso do simbólico, retorna no real (LACAN, 1981). Como efeito de sua foraclusão do mundo, Lear $e k$-siste, ou seja, ele se exclui do mundo das leis e se precipita, com uma voracidade assustadora, em lugar algum, fora do tempo/espaço (categorias essenciais à existência). ${ }^{21}$ Esse real que a loucura de Lear encenará abre outras fronteiras para a dimensão dos afetos.

${ }^{20}$ Conhecida expressão de Polonius, ao comentar a "loucura" de Hamlet [SHAKESPEARE, 1989, p. 248 (II, ii, 205-206)].

${ }^{21}$ A realização visual que Brook consegue dar a esse lugar (do) impossível é notável. 


\section{The Dragon and his wrath}

Os homens se tornam irados quando feridos, diz Aristóteles na Retórica [ARISTOTLE, 1994, p. 179 (II, 1379a 9)]. E orgé é o primeiro afeto a que ele se refere na definição dos páthe trazida acima. Ira (wrath) é também o afeto que Campbell destaca como característico de Lear (CAMPBELL, 1930). Pelo que vimos até agora, podemos afirmar que a ira é um afeto saliente nessa personagem. Porém, antes dela, pudemos observar um afeto tão complexo como o amor, em alguns de seus intricados matizes. Isso já é suficiente para se por em questão a ira como o afeto privilegiadamente característico em Rei Lear.

Lear é a "fera ferida" que se torna irascível como efeito de amores não correspondidos, ou melhor, ele emerge a partir de uma demanda desmesurada que rejeita todas as formas de amor que lhe são dadas, não apenas de suas filhas, mas de súditos leais, como o nobre Kent. Em sua voracidade pulsional, nenhuma forma de amor lhe satisfaz. E quanto mais ele exige, menos consegue. E nada lhe satisfaz. Um exemplo lapidar dessa posição paradoxal de demanda e recusa aparece quando Kent tenta chamar Lear à razão e à sobriedade, como convém a sua investidura, e ouvimos do rei: Come not between the Dragon and his wrath (I, i,121).

Aristóteles trata os afetos em termos de sua relação opositiva. Pelo que já pudemos indicar aqui, a psicanálise nos dá outro prisma para tratarmos a questão. Os afetos surgem de conflitos pulsionais, das tensões entre as exigências dessas forças que Freud chamou de "nossa mitologia" - a pulsão de vida, ou Eros, e a pulsão de morte, silenciosamente avassaladora, a guiar todo e qualquer organismo vivo.

O caso de Lear ilumina essa concepção sobre as pulsões e os afetos, como também nos faz refletir sobre a classificação antinômica de Aristóteles. O movimento aparentemente erótico de Lear em dividir seu reino entre as filhas, em nome do amor e com um pedido de amor, vem, desde sempre em Shakespeare, e em Brook em particular, banhado pela força destrutiva da pulsão de morte. Affirmation - as a substitute for uniting - belongs to Eros; negation - the successor of expulsion-belongs to the [drive] of destruction (FREUD, 1925/1961, p. 239). ${ }^{22}$

\footnotetext{
${ }^{22}$ Não deve passar desapercebida aqui a ressonância das duas vias de mudança apontadas por Aristóteles na Metafísica: a criação e destruição.
} 
O que parece uma dicotomia, a rigor é tratada na psicanálise de forma dialética: não se tem, de um lado, uma pulsão, e, de outro, outra, mas, sim, o que Freud identificou como o "fusionamento pulsional" (FREUD, 1920). Lear não vai do registro do amor para o da ira ou do ódio. Esses dois afetos basais se mesclam no jogo de espelhos que preside à constituição do humano: só temos conhecimento de nosso corpo, em sua totalidade, através de uma miragem, de uma imagem refletida num espelho, que pode ser arbitrariamente idêntica ou estranha a nós "mesmos". Daí Rimbaud dizer que je est un autre.

Lear põe em cena, de forma pulsionalmente violenta, a mescla que o neologismo de Lacan destacou como amó $(r)$ dio, ${ }^{23}$ no jogo homofônico que a língua francesa the permite: hainamoration. Os afetos são sempre, nessa perspectiva, a manifestação de uma tensão mais basal, de um movimento que faz essa força mítica que conecta o somático e o psíquico (a pulsão), que nunca tem sossego, que dirá nos dar sossego. Lear é agente e paciente nesse jogo, como convém a todo herói trágico.

Talvez seja por isso que Aristóteles tenha destacado, com instigante perspicácia, que os afetos (e suas mudanças) venham sempre acompanhados de prazer e dor [ainda tendo como referência a rica citação da Retórica trazida acima (ARISTOTLE, 1994, p. 173 - II, 1379a 8)].

A essa emblemática mescla de prazer e dor a psicanálise dá o nome de "gozo", um arranjo psíquico que podemos aproximar da conjugação feita por Aristóteles, onde impera o "quero mais" (um cigarro, um livro, uma ascensão na carreira... O fio metonímico é infindável, pois a demanda pulsional jamais encontrará $\mathrm{A}$ Coisa que lhe trará plena satisfação). Lear engendra esse paradoxo infernal para si ao rejeitar o que lhe é de direito usufruir, mas reivindicando poder gozar justamente daquilo que ele rejeitou. ${ }^{24} \mathrm{Em}$ outras palavras, ele abdica do universo

\footnotetext{
${ }^{23}$ A tradução adotada no Brasil para o neologismo de Lacan é amódio. Porém elegemos aqui a bela solução proposta pelo Prof. Teodoro Rennó Assunção.

${ }^{24} \mathrm{O}$ conceito de gozo é inextricável de uma rede complexa de conceitos analíticos. A partir do texto clássico de Freud "Para além do princípio do prazer" (FREUD, 1920), esta lógica paradoxal vem a ser a do prazer obtido na repetição de experiências dolorosas ou traumáticas, em sonhos, lembranças, relatos ou reedições de atitudes aparentemente dolorosas. Com Lacan, e as acepções que a língua francesa permite conjugar, o conceito de jouissance traz à baila não somente a dimensão marcadamente sexual do termo, como também um direito legal a ser desfrutado, tal como sugerem as expressões em português "fulano está em período de gozo", "gozar as férias".
} 
simbólico para poder lançar-se em uma vertiginosa demanda de gozo, cujo termo final será, inexoravelmente, a morte. Mas, antes dela, algumas mudanças importantes têm lugar.

\section{Duas mudanças possíveis: catarse e sublimação}

O clímax da peça de Shakespeare e do filme de Brook reside na "cena da tempestade", onde Lear, ensandecido, sábio e solitário, desafia os elementos e, claro, a própria morte. A compaixão inspirada por sua gradual recusa de afeto e abrigo que suas filhas lhe imputam, chega ao clímax, também para nós, espectadores. Uma compaixão que vem acompanhada por outro afeto que conhecemos não apenas através da Retórica, mas também da Poética, qual seja, o terror. Não creio ser por acaso que esses dois páthe sucedam a orgé, dentre os três afetos que o estagirita aponta na importante definição de afetos que vem acompanhando esse trabalho (cf. Rhet. II, 1378a 8).

Sem dúvida, a desmesura gozosa de Lear nos causa terror desde cedo na peça, e sua solidão e desamparo, nossa compaixão. Com isso indico que a dimensão desses dois afetos trágicos por excelência - terror e compaixão - diz respeito aos espectadores. Sobretudo, tais afetos só podem ter lugar desse lado da experiência dramática, posto que a autocomiseração e o medo de si seriam inadmissíveis na construção e na estatura do herói trágico.

Tais afetos só podem atravessar o palco para a plateia (ou a tela) na medida em que se constroem entre as duas instâncias, o que chamamos em teoria (literária e, sobretudo, psicanalítica) de identificação. $\mathrm{Na}$ Poética, Aristóteles já nos dá o caminho para pensarmos a questão: só podemos nos identificar com aquele que é nosso semelhante, porém um pouco melhor que nós [ARISTOTLE,1911, p. 44-46 (1453a 10ff)]. Estamos, portanto, em um plano bem diverso daquele em que se pensa a identificação em termos de empatia ou de simpatia, de sentir com o herói, de sentir o que ele sente, ou mesmo, de sentir por ele. O plano meta-psicológico que seguimos aqui nos alerta para o fato de que les senti-ments ["os sentidos mentem"] (LACAN, 2005, p. 17). Ou seja, os sentimentos estão na ordem da percepção/consciência, que é apenas uma pequena parte do que Freud chamou de "mental", ou de aparelho psíquico. A arte mobiliza muito mais do que somente nossa consciência, nossos sentidos. 
A psicanálise parece tomar Aristóteles mais a sério do que alguns críticos e comentadores. $\mathrm{O}$ mecanismo identificatório preside à constituição do "eu" e a sua sustentação no mundo. Isto é, a lógica do espelho (que vimos em operação em vários momentos de Rei Lear), é estrutural na formação do eu em sua dependência do outro e do Outro. $\mathrm{O}$ sujeito se forma e se sustenta entre o eu ideal (o que os outros gostariam que fôssemos) e o ideal de eu (o que idealmente gostaríamos de ser). ${ }^{25}$ É justamente essa contradança que uma análise busca des-arranjar, a fim de que o sujeito possa seguir seu caminho, de forma menos alienada ao outro (ainda que essa visada não esteja imune a coloraturas idealizantes, deve-se notar).

Para que uma obra dramática (poética, no sentido aristotélico) possa ter efeito e se constituir como tal, o mecanismo identificatório é condição sine qua non. Caso contrário, rejeitaremos o texto, a peça, o romance, como uma fantasia ou um delírio... Recuperando as formas de negatividade em Freud indicadas acima, podemos dizer que, para uma obra de arte ser levada a efeito e ter efeito, é necessário que se instaure a Verleugnung, a recusa em admitir sua completa falsidade (pseûdos). $\mathrm{O}$ poeta inglês Coleridge chamou esse mecanismo de suspension of disbelief. Sublinho que esse processo não se dá no âmbito da deliberação consciente, mas, sim, através de mecanismos inconscientes - como a identificação que sustentam o "engate" entre a obra de arte e o leitor/espectador.

Nesse sentido, os afetos (trágicos ou não) que nos inspiram uma criação artística têm assento nesse intricado vínculo entre o fruidor (o "gozoso") e a obra. Encontro em Lear um dos exemplos mais notáveis da literatura ocidental capaz de suscitar em nós os afetos de terror e compaixão, por mais turva que seja nossa identificação com ele. Uma possibilidade interpretativa parece residir justamente na complexidade afetiva da peça, em especial na desmesura de gozo do protagonista.

E se a obra se encarrega de construir a relação de identificação, caberá a ela desfazê-la, ou, ao menos, desconstruí-la. Essa desmontagem, sugiro, é levada a efeito através do processo catártico, cuja tradução mais pertinente me parece ser a de "depuração". Não podemos continuar presos identificatoriamente a Lear, a seu gozo, mesmo que sob o véu do

\footnotetext{
${ }^{25}$ Lacan desenvolve essa questão ao longo de toda sua obra. Em particular, destaco "Le stade du miroir comme formateur de la fonction du Je", "L'agressivité en psychanalyse" e "Propos sur la causalité psychique", todos publicados nos Écrits (LACAN, 1966).
} 
terror e da compaixão. You see me here, you Gods, a poor old man/ As full of grief as age; wretched in both! (II, iv, 270-271). Tal visão que Lear tem de si, já tão cedo quanto no segundo ato da peça, tem indícios presentes ao longo do texto no sentido de dar sustentação para que o processo catártico possa ser levado a efeito; para que possa haver uma mudança na natureza do laço entre herói e espectador, que tem nos afetos (de terror e compaixão) sua dimensão mais palpável. Mas esses indícios não são suficientes para promover uma mudança catártica. Para que haja mudança na relação do espectador com o herói, este deve ser seu agente.

O louco é um personagem tão isolado em sua experiência que ele tem a necessidade premente de reconhecimento (LACAN, 1981, p. 90; meu grifo), isto é, de inscrição na tessitura dos laços sociais. ${ }^{26}$ Entra em cena aqui não somente a questão da alienação psicótica, como também a tensão trágico-aristotélica da anagnórisis [ARISTOTLE, 1911, p. 41 (1452a 29 ff.)], da passagem da ignorância ao conhecimento - uma tensão que abre o filme de Peter Brook, como vimos acima.

Em Rei Lear, essa passagem se dá através de dois momentos de reconhecimento (no sentido trágico e lacaniano). Ambos se passam no quarto ato da peça, e ao final do filme de Brook. No primeiro episódio, Lear, já aos farrapos e tendo atravessado a tempestade (da loucura), encontra Gloucester, seu súdito fiel e, sobretudo, seu eu especular, seu counterfoil. Tal como Lear, Gloucester foi expulso do reino do simbólico, também por engendrações filiais (de Edmund, seu filho ilegítimo), e teve os olhos brutalmente arrancados por Cornwall, marido de Regan. Brook escolhe situar a cena de reconhecimento entre os dois personagens em uma praia, desoladamente vazia e, simbolicamente, um lugar de fronteira - um litoral. Um lugar que Edgar, o leal filho de Gloucester e súdito de Lear marca mais adiante na peça como O! Matter and impertinency mix'd;/ Reason in madness (IV, iv, 172-173). De fato, a loucura pode muito nos ensinar!

No texto de Shakespeare, Lear aparece com o corpo coberto de flores, como um lunático. No filme, ele está vestido, mas ainda com alguns resquícios de elementos da natureza [Nature's above art in that respect, diz Lear (IV, iv, 86)]. A câmera se alterna em focar um e outro personagem, antes do abraço (re)conciliador entre ambos.

\footnotetext{
${ }^{26}$ Ou seja, de um outro/Outro que garanta ao sujeito sua inscrição na ordem simbólica, como, por exemplo, "você é um pesquisador".
} 
A cegueira de Gloucester é outro caso clássico de ironia trágica: embora cego, ele vê/reconhece o rei em Lear e se ajoelha perante ele. A partir desse momento, Lear volta a falar em versos, isto é, ele retoma seu lugar de fala na ordem simbólica, como rei:

\section{Gloucester: Is 't not the King?}

Lear: Ay, every inch a king (...) (IV, iv, 107-108)

E mais adiante, quando Lear também reconhece Gloucester, este lhe pede: O! Let me kiss that hand! A resposta de Lear vem prenhe de sinais de que ele já passou por mudanças profundas, da ordem da génesis aristotélica: Let me wipe it first; it smells of mortality (IV, iv, 133-134). Mudança substancial, para quem supunha que poderia ser rei tendo renunciado ao reino e ao posto. Lear agora conhece de perto a finitude e seus limites. "Assunção da castração" é o nome dado pela psicanálise a esse tipo de mudança subjetiva. E a peça ainda lhe reserva mais mudanças de posição, mais do que de e nos afetos.

A segunda cena de reconhecimento se passa entre Lear e Cordélia, e dessa vez a reinscrição do protagonista é na ordem, também simbólica, da filiação:

Cord.: O! Look upon me, Sir

And hold your hand in benediction o'er me (...)

Lear: (...) I fear I am not in my perfect mind (...)

Do not laugh at me;

Fro, as I am a man, I think this lady

To be my child Cordelia. (IV, vii, 58-69)

A cena é assistida - significativamente - por Kent, o mais fiel dos súditos, em termos de lealdade ao rei e às leis, e pelo médico que está cuidando de Lear. Kent garante a inscrição do rei em seu reino: [You are] in your kingdom, Sir (IV, iv, 76). Já o médico revela-se muito mais um "médico da alma" do que a pshysician. Ele assegura à Cordélia: Be comforted, good Madam, the great rage,/ You see, is killed in him (...) (IV, iv, 78-79). 
Lear não é mais o "Dragão" que vimos surgir no início da tragédia. Não apenas ele deixa o domínio do "bestial" ${ }^{27}$ mas encontra na dimensão do humano um lugar que lhe caiba. É dessa posição que ele, reconciliado com Cordélia e re-inscrito na kin $(g)$ ship, lhe pede amparo e se (re)conhece frágil, mortalmente humano: You must bear with me./ Pray you now, forget and forgive: I am old and foolish (IV, iv, 83-84), são as palavras finais do pai que ainda terá que passar pela morte da filha, antes de chegar a seu télos, anunciado em sua primeira fala em termos de um crawl[ing] toward death (I, i. 40).

A essa posição que Lear agora ocupa, Lacan chamou-a de "entre duas mortes" (LACAN, 1986, p. 315). Trata-se de um mais além do que figura no preceito grego de gnôthi seautón ("conhece-te a ti mesmo"). $\mathrm{Na}$ experiência trágica (e no que dela comporta a experiência analítica), o protagonista, agente e paciente da ação, leva-a e se leva até às últimas consequências. E por ter podido "matar e deixar morrer o Dragão" que Lear pode agora ocupar o lugar de pequena grandeza que lhe cabe no mundo. Para além de uma mudança nos afetos de orgé, éleos e phóbos, Lear passa por uma mudança mais profunda e radical - ele ocupa outra posição na ordem simbólica, bem diversa daquela que apenas queria gozar de tudo que, equivocadamente, ele acreditava lhe ser de direito. E a partir dessa posição, no vazio entre duas mortes (uma simbólica e outra a vir, "real") e ao mesmo tempo engendrado por ela, que o herói pode (re)inventar-se um outro lugar, antes que seja tarde demais.

Cabe sublinhar que, diversamente de apenas ter feito com que sua ira fosse aplacada, como também de ter feito por onde ela poder ser apaziguada (praótés), Lear atravessou seu mundo de fantasias, foi além da dimensão da percepção-consciência (Freud), ou da dimensão da phantasía e da aisthessis, que Konstan destaca como central à elaboração aristotélica das "emoções" (KONSTAN, 2006, loc. 842) ${ }^{28}$ Essa nova posição do herói é efeito de um processo de criação - de si, de outra forma de estar no mundo -, a partir de sua descida aos infernos, de sua experiência de um vazio avassalador e nulificante. Lear gradualmente, pela via dos laços sociais da kin $(g)$ ship, consegue engendrar-se em um outro lugar no mundo, ainda que pela brevidade de apenas alguns poucos versos.

\footnotetext{
${ }^{27}$ Vale lembrar que o trágico, desde os gregos, põe em cena o debate da estatura do humano, entre os polos do bestial e do divino.

${ }^{28}$ A obra de Konstan foi consultada em seu formato Kindle.
} 
Em termos aristotélicos, essa mudança situa-se na ordem da génesis, em oposição à força destrutiva da pthorá (ARISTOTE, 1962, p. 379). Uma mudança que, sob a ótica de uma psicanálise helenizada, poderíamos chamar sublimação catártica. Lear é poeta de si próprio (ecoando a epígrafe de Lacan acima), cuja obra lhe possibilita por fim a sua busca dilacerante por um lugar (de gozo) no mundo.

\section{E nós?}

Onde ficamos nós, leitores/espectadores? Pela via da identificação, vivemos com Lear suas experiências, porém de forma vicária. Ou seja, em um engenhoso mecanismo de "faz de conta", ao qual Aristóteles chamou de mímesis, entramos no (i)mundo de Lear, mas sempre com um pé fora dele, no registro da negatividade que Freud chamou de Verleugnung, de um processo inconsciente no qual afirmamos, ao mesmo tempo em que negamos, a existência de algo.

Com base nesse nível de contradição, afastamo-nos da postulação aristotélica e, sobretudo, da postulação de que os páthe ("afetos") são uma função do juízo de valor, produzidos por indivíduos "conscientes dos motivos de outros e prontos a responder a eles" (apud KONSTAN, 2006, loc. 591).

O que a experiência poética nos ensina sobre o humano, antes da filosofia e da teoria, seja ela qual for, é que ele é produto da linguagem e, portanto, sujeito e assujeitado a ela. Nesse sentido, a palavra emerge com seu poder criador: não apenas criando o mundo, um fiat lux, mas em sua dimensão de cria-dor. Se experimentamos prazer na mímesis, na criação e na representação, em suma, no exercício sempre simbólico da linguagem, também padecemos dela, de suas leis e seus limites. Um exemplo: não existem palavras (significantes) que possam nos representar em nossa totalidade. O que equivale a dizer que não constituímos uma totalidade, a não ser imaginariamente.

Sob essa ótica, é secundária a tentativa (imaginária) de querer saber o que os gregos compreendiam por orgé, por exemplo, uma vez que cada língua cria seu universo de sujeitos e predicados. Podemos, no máximo, especular (no duplo sentido do étimo) o que eles nomearam como ira. Aliás, King Lear, já nos mostra como as palavras criam as coisas, em particular os afetos. Por exemplo, Lear chama seu afeto de wrath (I, i, 121). Já o médico nomeia-o por rage (IV, vii, 78), em um 
matiz significante que escapa à língua portuguesa. Antes da diferença entre as línguas e suas decorrentes culturas, não podemos saber se temos o mesmo sentimento do herói; sequer se ele mesmo o sente de maneira homogênea ou homóloga.

Lear nos leva junto na instabilidade enlouquecedora da linguagem, pela via da identificação, ou seja, pathetica-mente. Presos a e sendo presas do jogo mimético, somos confrontados com seu fim. Em outras palavras, em se tratando de linguagem (i.e., de representação), o fim é inexorável. O fim de uma peça/filme da magnitude de Rei Lear é prazerosamente triste: sofremos com suas perdas, com a sua morte. Porém, seu fim nos é libertador, como todo fim. Livramo-nos do terror e da compaixão que pontuaram nossa relação com o herói. A decantação, ou depuração catártica desses afetos se fará em outra temporalidade, diversa daquela da obra poética.

Em um efeito retroativo daquilo que chamamos, em crítica literária, de leitura, juntamos letras, cenas, falas, em um processo simbólico de produção (de sentido, de gozo). Discutimos a obra, escrevemos sobre ela, a ensinamos, recitamos, encenamos... Nesse sentido, perfazemos uma catarse sublimatória, isto é, geramos uma produção, e não uma criação ex nihilo (LACAN, 1986), como o fez Lear. Um processo de produção que nos mobiliza libidinalmente, e que aponta para outro lugar, fora do mundo dos objetos de gozo, onde se pode encontrar e apaziguar, de forma menos evanescente, o império da satisfação. É nessa vertente sublimatória que Brook, de maneira magistral, nos mostra a morte de Lear, em um close-up cada vez menor, em que o herói se depara com sua própria morte, e, ao fazer isso, aponta, significativamente, para "fora da tela".

Vamos olhar para lá, a fim de engendrarmos outras, novas, produções. Com prazer e dor.

Meus sinceros agradecimentos aos organizadores do evento "I Seminário Docere, delectare et mouere: emoções aristotélicas no cinema" (Centro de Convenções do Complexo Santuário do Caraça, de 10 a 13 de março de 2015), em especial à Profa. Dra. Maria Cecília de Miranda N. 
Nuntius Antiquus, Belo Horizonte, v. 11, n. 2, p. 9-32, 2015

Coelho pelo convite e pela oportunidade de trocas tão ricas. Um especial agradecimento ao Prof. Dr. Teodoro Rennó Assunção.

\section{Referências}

ARISTOTE. La métaphysique. Trad. e comment. J. Tricot. Paris: Librairie Philosophique J. Vrin, 1962 (tomo I).

ARISTOTLE. The Poetics. Ed. bilíngue e trad. S. H. Butcher. Londres: Macmillan, 1911.

ARISTOTLE. Categories and De interpretatione. Ed. e trad. J. L. Ackrill. Oxford: Clarendon Press, 1990.

ARISTOTLE. Art of Rhetoric. Ed. bilíngue e trad. J.H. Freese. Cambridge, Mass.: Harvard University Press, 1994.

AZEVEDO, A. M. V. F. A metáfora paterna na psicanálise e na literatura. São Paulo/ Brasília: Imprensa Oficial/Ed. UnB, 2001.

CAMPBELL, L. Shakespeare's tragic heroes: slaves of passion. Nova York: Barnes \& Noble, 1930.

FREUD. S. The interpretation of dreams. In: FREUD, S. The Standard Edition of the Complete Psychological Works of Sigmund Freud (S.E.). Ed. e trad. James Strachey. London: The Hogarth Press, 1958 [1900]. Vols. IV e V.

FREUD, S. The theme of the three caskets. In: FREUD, S. The Standard Edition of the Complete Psychological Works of Sigmund Freud (S.E.). Ed. e trad. James Strachey. London: The Hogarth Press, 1958 [1913]. Vol. XII, p. 290-301.

FREUD, S. The Unconscious. In: FREUD, S. The Standard Edition of the Complete Psychological Works of Sigmund Freud (S.E.). Ed. e trad. James Strachey. London: The Hogarth Press, 1957 [1915]. Vol. XIV, p. 159-215.

FREUD, S. A difficulty in the path of psychoanalysis. In: FREUD, S. The Standard Edition of the Complete Psychological Works of Sigmund Freud (S.E.). Ed. e trad. James Strachey. London: The Hogarth Press, 1955 [1917]. Vol. XVII, p. 135-144. 
FREUD, S. Beyond the pleasure principle. In: FREUD, S. The Standard Edition of the Complete Psychological Works of Sigmund Freud (S.E.). Ed. e trad. James Strachey. London: The Hogarth Press, 1955 [1920]. Vol. XVIII, p. 7-64.

FREUD, S. A short account of psychoanalysis. In: FREUD, S. The Standard Edition of the Complete Psychological Works of Sigmund Freud (S.E.). Ed. e trad. James Strachey. London: The Hogarth Press, 1961 [1924 (1923)].Vol. XIX, p. 191-209.

FREUD, S. Negation. In: FREUD, S. The Standard Edition of the Complete Psychological Works of Sigmund Freud (S.E.). Ed. e trad. James Strachey. London: The Hogarth Press, 1961 [1925]. Vol. XIX, p. 235-239.

HANNS. L. Dicionário comentado do alemão de Freud. Rio de Janeiro: Imago, 1996.

KERMODE, F. Shakespeare's language. Londres: The Penguin Books, 2001.

KONSTAN, D. The emotions of the Ancient Greeks: studies in Aristotle and classical literature. Toronto: University of Toronto Press, 2006.

LACAN, J. Écrits. Paris: Seuil, 1966.

LACAN, J. Le Séminarie, livre III: les psychoses. Paris: Seuil, 1981 [1955-1956].

LACAN, J. Le Séminaire, livre VII: l'éthique de la psychanalyse. Paris: Seuil, 1986 [1959-1960].

LACAN, J. Le Séminaire, livre XXIII: le sinthome. Paris: Seuil, 2005 [1975-1976].

MORA, J.F. Diccionario de Filosofia. Madrid: Alianza Editorial, 1987.

SHAKESPEARE, W. Hamlet. Ed. Harold Jenkins, The Arden Edition. London/New York: Routledge, 1989.

SHAKESPEARE, W. King Lear. Ed. Kenneth Muir, The Arden Edition. London/New York: Routledge, 1994.

SHAKESPEARE, W. Anthony and Cleopatra. New Swan Shakespeare. London: Longman, 1971. 